\title{
Analysis of genetic diversity among tropical and subtropical maize inbred lines using SSR markers
}

\author{
Vijay Kumar $^{1 *}$, S. K. Singh ${ }^{1}$, V. K. Malik ${ }^{1}$, A. K. Vishwakarma ${ }^{2}$, Vikas Gupta $^{3}$ and Vinay \\ Mahajan ${ }^{4}$ \\ ${ }^{1}$ Department of Genetics and Plant Breeding, Banaras Hindu University, Varanasi -221 005(U.P.), INDIA \\ ${ }^{2}$ Division of Genetics, Indian Agricultural Research Institute, New Delhi -110 012, INDIA \\ ${ }^{3}$ ICAR-Indian Institute of Wheat and Barley Research Karnal, Haryana-132001, INDIA \\ ${ }^{4}$ ICAR-Indian Institute of Maize Research, PAU Campus, Ludhiana 141004, (Punjab), INDIA \\ *Corresponding author. E-mail: v.k9181@ gmail.com
}

Received: March 30, 2017; Revised received: June 20, 2017; Accepted: November 3, 2017

Abstract: Genetic diversity of 24 tropical and subtropical elite maize lines was assessed at molecular level employing 42 Simple Sequence Repeats. A total of 107 alleles with an average of 2.55 alleles per locus were detected. The Polymorphism Information Content (PIC) values of 42 SSR loci ranged from 0.08 (UMC1428) to 0.68 (UMC2189 and UMC2332) with the overall calculated PIC mean value of 0.44 , whereas the Discrimination Rate (DR) value for SSR markers ranged from 0.09 (UMC2089) to 0.42 (UMC1311) with the average DR value of 0.26 . Pair-wise genetic similarity (GS) values, calculated by Jaccard's coefficients, ranged between 0.25 and 0.78 with a mean genetic similarity of 0.63 , indicating the existence of adequate amount of genetic divergence among the genotypes selected for the study. The cluster dendrogram separated all the inbred lines into six main clusters with sub clusters based on genetic similarity. Factorial analysis also confirmed a nearly similar pattern for grouping these inbred lines as presented by cluster dendrogram. In this study, SSR markers were found to be powerful tool for detection of genetic diversity in maize inbred lines. These findings could provide information for effective utilization of these materials for development of maize hybrids as well as for genetic improvement of inbred lines.

Keywords: Genetic diversity, Inbred lines, Maize, SSR markers, Polymorphism information content

\section{INTRODUCTION}

Maize (Zea mays L, $2 \mathrm{n}=20$ ) is one of the most important cereal crop in the world. Globally, it is known as queen of cereals because of its highest genetic yield potential. Maize provides at least $30 \%$ of the food calories together with rice and wheat to more than 4.5 billion people in 94 developing countries (Adetonah et al., 2016). Maize contributes maximum among the food cereal crops i.e. $40 \%$ annually $(>800 \mathrm{mt}$.) in the global food production (Jozsef and Zoltan 2013). In India, maize contributes nearly $9 \%$ in the national food basket and more than 400 billion to the agricultural GDP at current prices apart from generating employment to over 1000 million man-days (Dass et al., 2012). For the effective conservation and utilization of maize genetic resources, a clear understanding of genetic diversity and its relationships with heterosis is essential for any crop improvement programs. The range of heterosis in crops like maize is depending on the genetic diversity present among the genotypes. Based on quantitative genetic theory, the probability of producing unique genotypes possessing desirable gene combination depends on the enrichment of the parents in proportion to the number of genes by which parents diverge.

The genetic diversity among parental lines is necessary to supply an ample quantity of allelic variation that can be used to generate new favorable gene combinations. Several previous reports indicate that, performance of $\mathrm{F}_{1}$ depends on the genetic variability of parental lines (Devi and Singh, 2011; Prasanna, 2012; Pedram et al., 2012). There are different methodologies exist for the assessment of genetic diversity in maize like morphological traits (Goodman and Bird 1977), isozymes (Revilla et al., 1998) and molecular marker based diversity assessment using Random Amplified polymorphic DNA (RAPDs), Amplified fragment length polymorphism (AFLP) and simple sequence repeats (SSRs) (Smith et al., 1997; Ajmone Marsan et al., 2001; Moses et al., 2015). Since the morphological characters are influenced by the environment, they do not reliably provide genetic diversity information of germplasm. Molecular markers are found free from such limitations and capable to provide more precise information on genetic diversity. The use of molecular markers for diversity analysis serves as a useful tool to discriminate between closely related individuals from different breeding sources (Moses et al., 2015). 
Modern molecular markers approach facilitate a reliable selection of parents for hybridization and more precise assessment of the levels of genetic variations present in parental lines, especially from different genetic backgrounds (Lu et al., 2009). Among molecular marker systems, efficacy of SSR markers in determining genetic variability and relationships among maize germplasm has been effectively demonstrated in several studies (Senior et al., 1998; Kassahun and Prasanna, 2003; Legesse et al., 2007; Kostova et al., 2006). SSR markers are PCR-based, co-dominant, less costly, robust, reliable, highly reproducible, with greater discriminatory ability and are more widely available than other molecular markers like RFLP's and RAPD's etc. (Pushpavalli et al., 2001; Prasanna and Hoisington, 2003). A clear understanding of variability and its relationship with heterosis must be understood in order to undertake any heterosis breeding programme. Therefore, the present study was undertaken to evaluate genetic diversity among tropical and subtropical elite maize lines using SSRs markers.

\section{MATERIALS AND METHODS}

Plant material and SSR markers: Plant material comprised of 24 tropical and sub tropical maize inbred lines from different backgrounds (Table 1) was used to study the diversity at molecular level using 42 SSR markers distributed on all chromosomes of maize genome (Table 2). The primer information of these SSR markers is available in public domain (MaizeGDB http://www.maizegdb.org). Seed materials were grown during Kharif season following recommended package of practices (Parihar et al ., 2011) at the research farm of IARI, New Delhi and further genotyping work was carried out at Maize Genetics Unit, IARI, New Delhi.

DNA isolation and quantification: A modified CTAB method was used for isolation of genomic DNA from a pooled sample of fresh leaves of 5 plants from each inbred lines (Saghai et al., 1984). The working DNA samples were stored at $4{ }^{\circ} \mathrm{C}$ and stock solutions at $-20^{\circ} \mathrm{C}$ (Celfrost BFS 345-S). Quantification of DNA samples was done using a Spectrophotometer (Bio-Tek Instruments, USA) and absorbance was recorded at $260 \mathrm{~nm}$ and $280 \mathrm{~nm}$. The quality of DNA samples was checked using $0.8 \%$ agarose gel electrophoresis with a known concentration of uncut $\lambda$ DNA to adjust final concentration for use in PCR reaction.

PCR amplification: DNA amplification was carried out by PCR with a reaction mixture of $15 \mu \mathrm{l}$, containing $5 \mathrm{ng}$ of genomic DNA template, $1 \mu \mathrm{M}$ each of forward and reverse primers, $0.2 \mathrm{mM}$ dNTPs, $0.5 \mathrm{U}$ Taq DNA polymerase and $1.5 \mathrm{mM} \mathrm{MgCl}$ (Fermentas), in a Peltier Thermal cycler-100 or Dyad (MJ Research, USA). The cycling parameters for PCR amplification consisted of initial denaturation at $94^{\circ} \mathrm{C}$ for $4 \mathrm{~min}$ followed by $94^{\circ} \mathrm{C}$ for 1 min denaturation, primer annealing at $55-65^{\circ} \mathrm{C}$ (depending on the respective primer annealing temperature) for $1 \mathrm{~min}$ and at $72^{\circ} \mathrm{C}$ for 2 min for primer extension and then 35 cycles of denaturation to extension. The final cycle for primer extension was performed at $72^{\circ} \mathrm{C}$ for $7 \mathrm{~min}$ and then stored at $4^{\circ} \mathrm{C}$. The amplified PCR products were resolved on $3.5 \%$ metaphor agarose gel (Fermentas) along with 100 bp ladder (Fermentas) using a horizontal submarine gel electrophoresis system (Biorad Submarine Gel Electrophoresis Unit, USA). The gel was run in $1 \mathrm{x}$ Tris/Borate/EDTA (TBE) buffer at a constant voltage of $80 \mathrm{~V}$ for about $4 \mathrm{hr}$ (until the tracking dye migrated to the end of the gel). The gel images were captured using a Gel Documentation System (Alpha Imager, USA).

Scoring and analysis SSR's data: Marker data was recorded as ' 1 ' for the presence and ' 0 ' for the absence of a band whereas, the diffused bands or bands depicted ambiguity in scoring were considered as missing data and designated as ' 9 ' in the data matrix. Null allele for any specific marker in a genotype was considered as absence of primer binding site, after reruns with specific check and was designated as ' 0 '. The polymorphism information content (PIC) was performed as described as (Bantte and Prasanna, 2003). PIC is a measure of allele diversity at a locus which is equal to $1-\Sigma f i^{2}$, where $f$ is the frequency of $i^{\text {th }}$ allele. Discrimination Rate (DR) was calculated according to Selvi et al. (2005). Genetic similarity (GS) based on SSR data was calculated for all possible pairs of genotypes using Jaccard's coefficient (J) (Jaccard, 1908) based on the formula, GSJ $=\mathrm{N}_{11} /\left(\mathrm{N}_{11}+\mathrm{N}_{10}+\mathrm{N}_{01}\right)$, where $\mathrm{N}_{11}$ is the number of alleles present in both individuals, $\mathrm{N}_{10}$ is the number of alleles present only in one of the pair (individual i) and $\mathrm{N}_{01}$ is the number of alleles present only in the individual $\mathrm{j}$. The similarity matrix was implemented by using UPGMA (Unweighted Paired Group Method using Arithmetic Averages) with average linkage. Goodness of fit of clustering was also tested by estimating cophenetic values using COPH and MXCOMP options of the NTSYSpc version 2.2 (Rohlf, 1989).

\section{RESULTS AND DISCUSSION}

A total of 42 SSR markers were used to understand the genetic relationship among 24 tropical and subtropical elite maize inbred lines collected from different maize research centers in India. The SSR markers failed to amplify any band and showed monomorphic pattern was not included in any calculation. The majority of SSR fragments size ranged from $50-200 \mathrm{bp}$. Analysis of molecular polymorphisms led to detection of a total of 107 alleles, ranged from 2 to 5 with an average of 2.55 alleles per locus (Table 2). A total of 23 SSR loci reported with two alleles, 16 with three alleles, 2 with four alleles and remaining one locus revealed five alleles. The repeat motifs information of SSR loci analyzed in present study were as follows: tri-repeat motif 
Table 1. Seed source/pedigree of 24 maize inbreds investigated under present study.

\begin{tabular}{llll}
\hline S. No. & Name of inbred lines & Sources/Pedigree & Types \\
\hline 1 & DM-RIL-47 & GENETICS IARI & Subtropical \\
2 & NAI-147 & NAGANHALLI/EV 25-CD (Y) AIM-C7 & Subtropical \\
3 & CM-142-393-1 & GENETICS IARI /1PA 3-20-1-1-1 & Subtropical \\
4 & MGU-138-3053 & GENETICS IARI & Tropical \\
5 & CM-212-3142 & GENETICS IARI /CI 21 E & Subtropical \\
6 & CML-152-3058 & CIMMYT/ S8862Q-1-4-4-5-B-\#/Pop62 & Tropical \\
7 & SE-547-3037 & GENETICS IARI & Tropical \\
8 & BLSB-RIL-92 & GENETICS IARI & Subtropical \\
9 & VQL-1 & GENETICS IARI/(CM-212XCML-180) BCJ P1@b@b@b@b-\# & Subtropical \\
10 & HKI-193-1 & KARNAL/CML193 & Subtropical \\
11 & CM-152 & GENETICS IARI/POP 31 C4 HS bulk (Alm) \#\#\#@b-\#\#\#-@\#,U3-1 & Subtropical \\
12 & HKI-209 & KARNAL/Pop10 & Subtropical \\
13 & HKI-287 & KARNAL/CML 287 & Subtropical \\
14 & SC-7-2-1-2-6-1 & DMR & Subtropical \\
15 & CML-119 & CIMMYT/B807-2-3-3-3-1-4-b1-b1\#-b1/ R 109 & Tropical \\
16 & HKI-1025 & KARNAL/BC175 & Subtropical \\
17 & HKI-1105 & KARNAL/Cargil 633 & Subtropical \\
18 & HKI-335 & KARNAL/POOL10 & Subtropical \\
19 & HKI-323-8 & KARNAL/POOL28 & Subtropical \\
20 & CML-147 & CIMMYT/Pob63c2HC53-1-1-B-B-B-9-B-B-\#/POp63 & Tropical \\
21 & CML-150 & CIMMYT/P 24 QPM & Tropical \\
22 & CML-395 & CIMMYT/11TA & Tropical \\
23 & HKI-162 & KARNAL/CML162 & Subtropical \\
24 & CML-421-CML-170 & CIMMYT & Tropical \\
\hline
\end{tabular}

(39), di-repeat and tetra-repeat (one loci each), while the information about one repeat motifs was not available at Maize GDB. The tri and tetra repeats are having high polymorphism as compared to di-repeats.

The Polymorphism Information Content (PIC) value of a SSR locus is influenced by the number of alleles (allele richness) as well as distribution of these alleles across the genotypes. PIC values of the SSR loci varied from 0.03 (umc1178) to 0.68 (umc1353) with overall mean value of 0.44 (Table 2 ). This overall PIC value may be influenced by various factors, viz., the nature of germplasm used for the study; number of SSR loci as well as inbred lines analyzed; nature and type of repeats of SSR loci and the methodology employed for allele detection (agarose versus PAGE). Out of 42 SSR markers, only 28 gave rise to high $(\geq 0.40)$ PIC values; such loci could be highly useful in genotype differentiation and genetic diversity analysis among the inbred lines (Gurung et al., 2010). Rest of the fourteen SSRs gave low $(\leq 0.40)$ PIC values indicating their inability in discriminating the genotypes. The markers amplifying high number of monomorphic bands were having low PIC value whereas the markers showing more unique and null alleles were having high PIC value (Nepolean et al., 2013). Discrimination rate (DR) ranged from 0.09 (umc1428) to 0.42 (umc1452) with an average of 0.26 . Out of 42 SSR markers, 14 gave rise to high DR values $(\geq 0.30)$, while remaining 28 primers depicted low DR values $(<0.30)$. PIC values and DR gave a positive significant correlation of 0.58 . Except few of markers with high PIC value did show high DR, however, vice versa was always not true. Some markers like umc1596, umc1428, umc1913, umc2089, umc2017 and umc2021 gave low DR $(<0.29)$, which also showed very low PIC values. The pair wise genetic similarity was calculated by Jaccard's coefficients, this ranged from 0.25 between two pairs (VQL-1 with HKI-193-1) and 0.78 between (CM -142-393-1 with HKI 1025; HKI 1105 with DMRIL47 ) with an average value of 0.63 . Cluster analysis revealed a good fit to the data matrix as evidenced from high cophenetic correlation coefficient value of 0.58 .

The factorial analysis showed a scattered distribution of 24 maize inbred lines in the two dimensional plot diagram (Figure 2), confirmed a nearly similar pattern for grouping as presented in cluster dendrogram (Figure 1), and separated all the inbreds into four major groups. Group II was the largest consisted of eight inbred lines namely CML-395, SE-547-3037, BLSBRIL-92, SC-7-2-1-2-6-1, CML-421-CML-170, CML119, NAI-147 and HKI-287. Similarly group I composed of six HKI323-8, CML1-147, CM-212-3142, CM-142-393-1, DM- RIL-47 and HKI-162, Group III with four HKI-209, MGU-138-3053, CM-152 and HKI -1105, group IV with HKI-1025, HKI-193-1, VQL-1, CML-150 and HKI-335 inbred lines. One inbred line CML-152-3058 did not fall into any group. From the result of this study, it was found that some pairs of inbred lines were consistently close falling in one cluster as per the pedigree details, but other inbreds did not follow this pattern. Clustering of inbred lines indicate the presence of enough genetic diversity among maize inbred lines collected from different maize research centers. In sub-clusters presence of inbred lines of different group indicate the minor genetic difference be- 
Vijay Kumar et al. / J. Appl. \& Nat. Sci. 9 (4): 2427 - 2433 (2017)

Table 2. Information of 42 SSR loci with bin location, repeat type, product size, No. of amplified alleles, polymorphism information content (PIC) and discrimination rate (DR).

\begin{tabular}{|c|c|c|c|c|c|c|c|c|}
\hline S. No. & SSR locus & Bin & Repeat type & Repeat & Product size & Amplified alleles & PIC & DR \\
\hline 1 & UMC1452 & 1.04 & $(\mathrm{GCC}) 4$ & tri & 96 & 2 & 0.23 & 0.28 \\
\hline 2 & UMC1122 & 1.06 & $(\mathrm{CGT}) 7$ & tri & 156 & 3 & 0.66 & 0.37 \\
\hline 3 & UMC2151 & 1.06 & $(\mathrm{CAG}) 4$ & tri & 127 & 3 & 0.49 & 0.30 \\
\hline 4 & UMC1446 & 1.08 & (TAA)7 & tri & 160 & 2 & 0.47 & 0.24 \\
\hline 5 & UMC2189 & 1.10 & $(\mathrm{CAG}) 4$ & tri & 160 & 2 & 0.68 & 0.34 \\
\hline 6 & UMC1534 & 1.10 & $(\mathrm{AAG}) 5$ & tri & 92 & 3 & 0.44 & 0.24 \\
\hline 7 & UMC1353 & 1.10 & $(\mathrm{AAC}) 4$ & tri & 159 & 3 & 0.66 & 0.35 \\
\hline 8 & UMC1262 & 2.02 & (GTC)4 & tri & 145 & 2 & 0.38 & 0.20 \\
\hline 9 & UMC2125 & 2.05 & (GAG)7 & tri & 151 & 2 & 0.33 & 0.17 \\
\hline 10 & UMC2129 & 2.07 & $(\mathrm{CGC}) 5$ & tri & 80 & 3 & 0.45 & 0.28 \\
\hline 11 & UMC1256 & 2.09 & $(\mathrm{CAT}) 5$ & tri & 143 & 2 & 0.48 & 0.25 \\
\hline 12 & UMC2103 & 3.00 & $(\mathrm{GCG}) 5$ & tri & 158 & 3 & 0.54 & 0.28 \\
\hline 13 & UMC2050 & 3.07 & (CGC)4 & tri & 85 & 2 & 0.36 & 0.30 \\
\hline 14 & UMC1813 & 3.09 & $(\mathrm{CAG}) 8$ & tri & 121 & 2 & 0.54 & 0.28 \\
\hline 15 & UMC1010 & 3.09 & (GA) 10 & di & 94 & 3 & 0.50 & 0.28 \\
\hline 16 & UMC1228 & 4.01 & $(\mathrm{CAG}) 10$ & tri & 50 & 3 & 0.66 & 0.35 \\
\hline 17 & UMC1313 & 4.09 & $(\mathrm{CTT}) 5$ & tri & 86 & 2 & 0.52 & 0.27 \\
\hline 18 & UMC2011 & 4.10 & NA & NA & 155 & 3 & 0.37 & 0.30 \\
\hline 19 & UMC1597 & 5.03 & (CCT)4 & tri & 107 & 2 & 0.21 & 0.11 \\
\hline 20 & UMC2298 & 5.04 & $(\mathrm{GCG}) 4$ & tri & NA & 3 & 0.53 & 0.27 \\
\hline 21 & UMC1171 & 5.04 & (GTT)4 & tri & $90-100$ & 3 & 0.54 & 0.28 \\
\hline 22 & UMC1153 & 5.09 & (TCA)4 & tri & 111 & 2 & 0.50 & 0.26 \\
\hline 23 & UMC1818 & 6.01 & (CAG)6 & tri & 148 & 2 & 0.47 & 0.24 \\
\hline 24 & UMC1178 & 6.02 & (GGC)6 & tri & 160 & 2 & 0.45 & 0.28 \\
\hline 25 & UMC1857 & 6.04 & (TAA)6 & tri & 146 & 2 & 0.41 & 0.22 \\
\hline 26 & UMC2364 & 7.01 & $(\mathrm{GGA}) 7$ & tri & NA & 4 & 0.45 & 0.36 \\
\hline 27 & UMC2325 & 7.01 & (TGG)7 & tri & NA & 3 & 0.29 & 0.36 \\
\hline 28 & UMC1428 & 7.02 & $(\mathrm{CCG}) 5$ & tri & 105 & 2 & 0.08 & 0.14 \\
\hline 29 & UMC1708 & 7.04 & (GGA)4 & tri & 84 & 4 & 0.66 & 0.35 \\
\hline 30 & UMC2332 & 7.04 & (CTC) 5 & tri & NA & 2 & 0.68 & 0.34 \\
\hline 31 & UMC1913 & 8.02 & (TTG)6 & tri & 217 & 3 & 0.29 & 0.19 \\
\hline 32 & UMC1872 & 8.02 & (GCA)6 & tri & 141 & 3 & 0.50 & 0.30 \\
\hline 33 & UMC1735 & 8.03 & $(\mathrm{AGC}) 5$ & tri & 97 & 2 & 0.34 & 0.18 \\
\hline 34 & UMC1596 & 9.01 & (GGC)6 & tri & 157 & 2 & 0.50 & 0.25 \\
\hline 35 & UMC2336 & 9.02 & (TGT)4 & tri & 102 & 3 & 0.39 & 0.28 \\
\hline 36 & UMC2133 & 9.05 & $(\mathrm{AGC}) 4$ & tri & 160 & 3 & 0.42 & 0.30 \\
\hline 37 & UMC2089 & 9.07 & (CGC)4 & tri & 178 & 2 & 0.15 & 0.09 \\
\hline 38 & UMC2017 & 10.03 & $(\mathrm{CAA}) 4$ & tri & 52 & 2 & 0.29 & 0.15 \\
\hline 39 & UMC1280 & 10.04 & (AAT)7 & tri & 111 & 2 & 0.40 & 0.21 \\
\hline 40 & UMC2043 & 10.05 & (TCC) 4 & tri & NA & 2 & 0.53 & 0.28 \\
\hline 41 & UMC1311 & 10.60 & (TCTT)4 & tetra & 136 & 5 & 0.55 & 0.42 \\
\hline 42 & UMC2021 & 10.07 & (TGG) 4 & tri & NA & 2 & 0.28 & 0.14 \\
\hline Total & & & & & & $107 / 42$ & $\begin{array}{l}18.62 / 4 \\
2\end{array}$ & $\begin{array}{l}11.07 / \\
42\end{array}$ \\
\hline Mean & & & & & & 2.55 & 0.44 & 0.26 \\
\hline
\end{tabular}

tween these lines of a main cluster. Such grouping may expose a slight gene flow among inbred lines of different origin. According to Sun et al., (2001), the discrepancy between pedigree and molecular markersbased genetic diversity estimates may be caused by selection pressure for different breeding objectives. The results also revealed that pattern of grouping did not match well with available pedigree information which is in accordance with the results reported in oats (O’Donoughue et al., 1994), bread wheat (Barrett et al., 1998; Almanza-Pinzon et al., 2003, Soleimani et al., 2002).

This analysis led to detection of 107 alleles (Table 2), with a mean of 2.55 alleles per locus. Earlier studies reported 4.9 alleles using 85 SSR markers (Warburton et al., 2002), 3.25 alleles with 36 SSR loci (Bantte and Prasanna, 2003), and 5.3 alleles using 80 SSR loci (Vaz Patto et al., 2004). In this study, mean of alleles per locus was considerably lower than reported earlier in the maize. Karanja et al., (2009) reported 2.0 averages of alleles using 14 loci. The SSRs used in this study were tri-repeat motifs (thirty nine loci), di and tetra-repeat (one locus each) whereas; information of one repeat motif was not available at MaizeGDB. All these loci were found to be significantly associated with the genome as depicted by the average number 


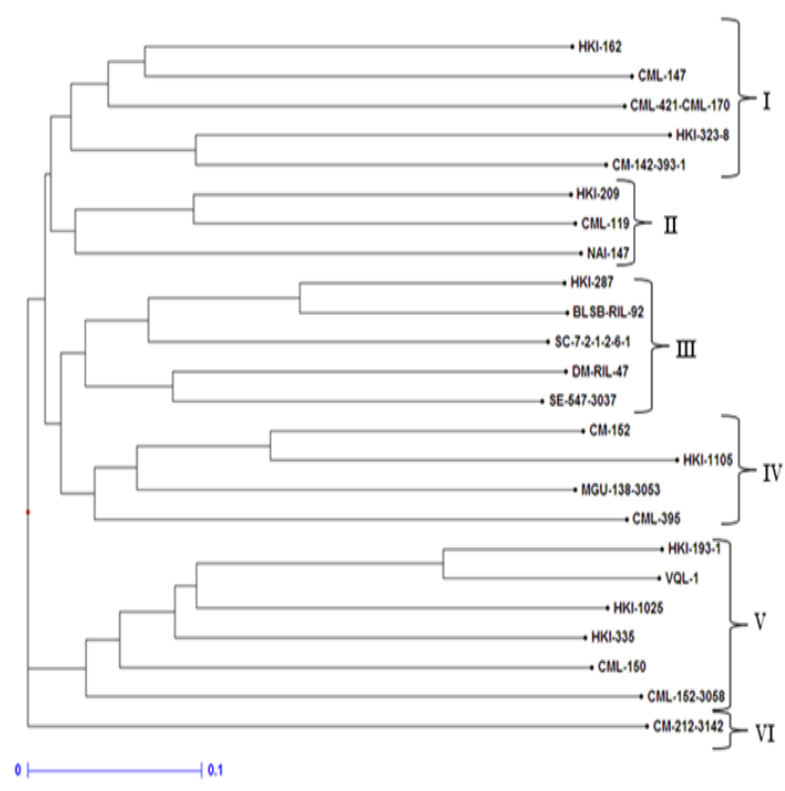

Fig.1. Dendrogram generated based on 42 SSR loci to expose the genetic relationships among 24 maize inbred lines.

Foctorial analysis: Axes $1 / 2$

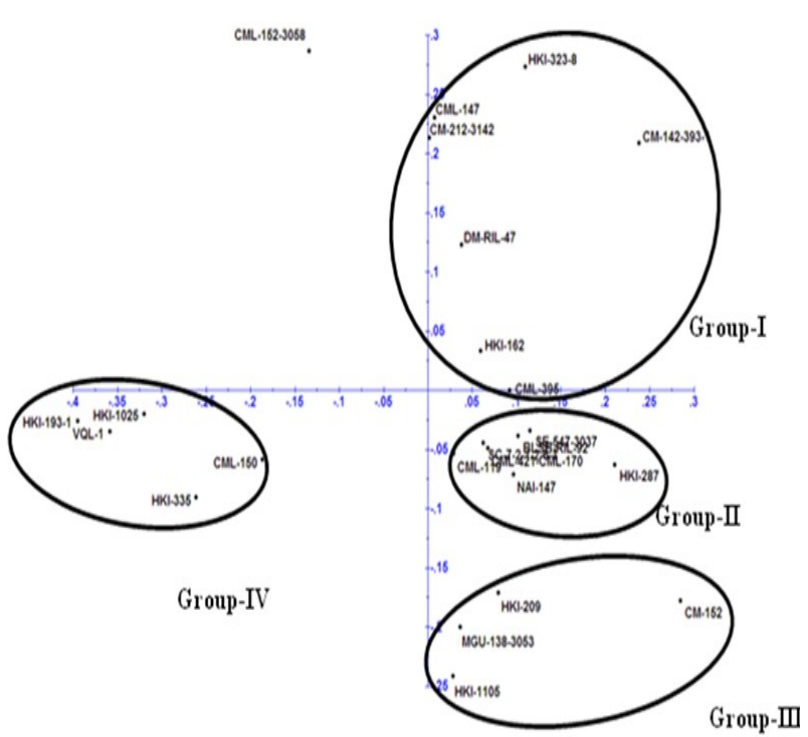

Fig.2. Factorial analysis revealed the genetic relationships among the maize inbreds.

alleles (2.55) amplified per primer (Table 2). The mean PIC and DR values were 0.44 and of 0.26 respectively in our study, which support the observations made by other workers (Legesse et al., 2007; Enoki et al., 2002). In the present study, the less PIC value might be due to the use of metaphor agarose gel electrophoresis, whereas polyacrylamide gel or automated analysis approaches used by (Yap et al., 1996; Tobias et al., (2008) reported high PIC values.

The inbred lines used in the present investigation are less dissimilar in term of pedigree information as compared to previous reports (Prasanna and Hoisington,
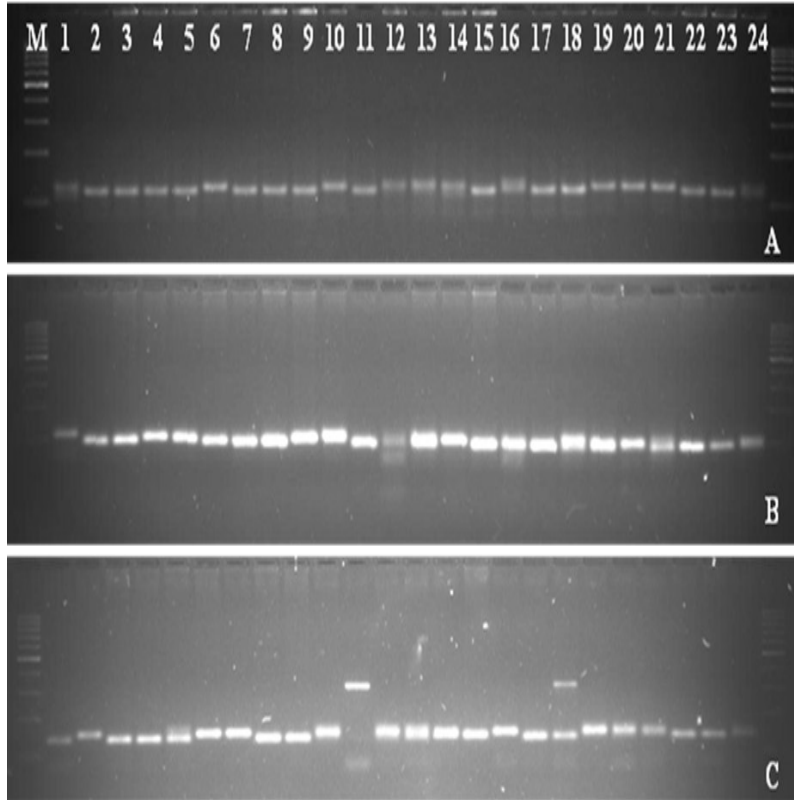

Fig.3. SSR polymorphisms in 24 selected maize inbred lines, illustrated by umc1415 (A); umc2151 (B) and umc2129 (C). The lane order (1 to 24) is same as the list of genotypes presented in table.1.

2003; Warburton et al., 2002; Vaz Patto et al., 2004). This may be due to many of the lines used for present investigation are from same groups viz, HKI, CML and CM (Table 1). Genetic similarity as analyzed by Jaccard's coefficient indicated considerable variability among the inbred lines used in present study. The average genetic similarity among the lines $(0.63 \%)$ was relatively low, indicating high level of polymorphism between the inbred lines. This has also been suggested by various authors (Bantte and Prasanna, 2003; Beyene et al., 2005; Sharma et al., 2010). The dendrogram created using UPGMA clustering algorithm fit well with the similarity matrix with high cophenetic correlation $(\mathrm{r}=0.55)$. The dendrogram placed these inbred lines into six main clusters with minor sub grouping within the major clusters. However, the grouping by UPGMA analysis did not follow the genetic relatedness as indicated by their pedigree data.

Present investigation revealed that, PIC alone will not give true representation of the informativeness of a SSR marker, but DR may also be taken into consideration. Similarity matrices obtained using the markers of high DR and the whole set of data fits wells to the goodness of fit test. Selvi et al., (2005) proposed the use of DR in identifying primers combination for AFLP analysis. The result indicated that, DR may be a more reliable indicator for selecting markers for their ability to differentiate lines as against widely accepted PIC values. The factorial analysis revealed a nearly similar pattern for grouping of inbred lines as cluster dendrogram. All the genotypes showed a clear grouping except in group II. Group II depicted a partial 
overlapping between inbred lines indicating that these lines were previously derived from the same group. Finally it could be concluded that, for genetic diversity analysis and grouping the genotypes, molecular distances is the most effective method. Similar study taking more number of genotypes and more number of markers may give rise to a better understanding of the situation. In present study, estimation of accurate genetic relations among parental lines may be useful for determining the material should be combined in crosses for obtaining superior genotypes in future breeding programs. Selection of parents from each cluster and crossing them in a series of breeding fashion could be highly fruitful.

\section{Conclusion}

Marker based studies are repeatable and give insight in the variability present at DNA level. In the present study diversity assessed using molecular markers visualized the genetic differences in the maize genotypes. The average PIC value of 0.44 indicated that the SSR markers are a powerful tool for detection of genetic diversity. Molecular markers separated all the inbred lines into six main clusters and the genotypes from the diverse clusters may be a potential candidates for inbred and hybrid development.

\section{ACKNOWLEDGEMENTS}

Senior author gratefully acknowledge the help and guidance for conducting the research work provided by Dr. Firoz Hossain, (Maize Genetics Unit, Division of Genetics, I.A.R.I., New Delhi-110012).

\section{REFERENCES}

Adetonah, S., Coulibaly, O., Satoguina, H., Sangare, A. and Dossavi-yovo, N.H. (2016). Gender analysis in grain maize value chain in Northern and Central Benin. International Journal of Research in Social Sciences. 6(7): 51-64.

Ajmone Marsan P, Gorni C, Chitto` A, Redaelli R, Van Vijk R, Stam P, and Motto M. (2001). Identification of QTLs for grain yield and grain-related traits of maize (Zea mays L.) using an AFLP map, different testers, and cofactor analysis. Theor Appl Genet. 102: 230-243.

Almanza-Pinzon M.I., Khairallah, M., Fox P.N. and Warburton, M.L. (2003). Comparison of molecular markers and coefficients of parentage for the analysis of genetic diversity among spring bread wheat accessions. Euphytica 130: 77-86.

Bantte, K. and Prasanna, B.M. (2003). Simple sequence repeat polymorphism in Quality Protein Maize (QPM) lines. Euphytica. 129: 337-344.

Barrett, B.A. and Kidwell, K.K. (1998). AFLP-based genetic diversity assessment among wheat cultivars from the Pacific Northwest. Crop Science. 38: 1261-1271.

Beyene, Y., Botha, A. and Alexander, A.M. (2005). A comparative study of molecular and morphological methods of describing genetic relationships in traditional Ethiopian highland maize. African Journal of Biotechnology.
4(7): 586-595.

Parihar, C.M., Jat, S.L., Singh, A.K., Sai Kumar, R., Hooda, K.S., Chikkappa G.K. and Singh D.K. (2011). Maize Production Technologies in India. DMR Technical Bulletin2011/---. Directorate of Maize Research, Pusa Campus, New Delhi-110 012. Pp 30.

Dass, S., Jat, S.L., Chikkappa G.K., Parihar C.M., Kumar, B. and Singh A.K. (2012). Maize improvement towards food security: genetic and technological perspectives. In: conference programme book of 1st ICC India Grains Conference organized by ICC in partnership with ICRISAT at New Delhi from 16-18th January, 12: 24-25.

Devi, P. and Singh N.K. (2011). Heterosis, molecular diversity, combining ability and their interrelationships in short duration maize (Zea mays L.) across the environments. Euphytica. 178: 71-81.

Enoki, H., Santo, H. and Koinuma, K. (2002). SSR analysis of genetic diversity among maize inbred lines adapted to cold region of Japan. Theoretical and Applied Genetics. 104: 1270-1277.

Goodman M.M, and Bird RMcK. (1977). The races of maize IV: tentative grouping of 219 Latin American races. Economic Botany. 31:204-221.

Gurung D.B., George M.L.C., and Dela Cruz Q.D. (2010). Analysis of Genetic Diversity within Nepalese Maize Populations Using SSR Markers. Nepal Journal of Science and Technology. 11: 1-8.

Jaccard, P. (1908). Nouvelles recherches sur la distribution florale. Bulletin de la Societe Vaudoise Sciences Natureiies. 44: 223-270.

Jozsef P. and Zoltan L (2013). Global Socio-Economic and Environmental Dimensions of GM Maize Cultivation. Food and Nutrition Sciences. 4: 8-20.

Karanja, J., Amugune1, N.O., Ininda, J., Kimatu, J.N. and Damson, J.W. (2009). Microsatellite analysis of the correlation between molecular and morphological traits in assorted maize inbred lines. African Crop Science Journal. 12: 133-144.

Kassahun, B. and Prasanna, B.M. (2003). Simple sequence repeat polymorphism in Quality Protein Maize (QPM) lines. Euphytica. 129: 337-344.

Kostova, A., Todorovska E., Christov N., Hristov K., and Atanassov, A. (2006). Assessment of genetic variability induced by chemical mutagenesis in elite maize germplasm via SSR markers. Journal of Crop Improvement. 16: 37-48.

Legesse, B.W., Myburg, A.A., Pixely, K.V. and Botha, A.M. (2007). Genetic diversity of maize inbred lines revealed by SSR markers. Hereditas. 144: 10-17.

Lu Y., Yan J., Guimara es C.T., Taba S. and Hao Z. (2009). Molecular characterization of global maize breeding germplasm based on genome-wide single nucleotide polymorphisms. Theoretical and Applied Genetics. 120: 93-115.

Moses A.A., Abebe M., Malaku G., Essie B., Vernon G., Eric D. and Ladejobi F. (2015). Diversity Assessment of Drought Tolerant Exotic and Adapted Maize (Zea mays L.) Inbred Lines with Microsatellite Markers. Journal of Crop Science and Biotechnology. 18 (3): 147-154.

Nepolean T., Singh I., Hossain F., Pandey N. and Gupta H.S. (2013). Molecular characterization and assessment of genetic diversity of inbred lines showing variability for 
drought tolerance in maize. Journal of Plant Biochemistry and Biotechnology. 22:71-79.

O'Donoughue, L.S., Souza, E., Tanksley, S.D. and Sorrells. M.E. (1994). Relationships among North American oat cultivars based on restriction fragment length polymorphisms. Crop Science. 34: 1251-1258.

Pedram K., Ghizan S., Jothi M.P., Nur A.P.A., and Ahmad S. (2012). Molecular characterization of tropical sweet corn inbred lines using microsatellite markers. Maydica. 57: $154-163$.

Prasanna B.M. (2012). Diversity in global maize germplasm: characterization and utilization. Journal of Biosciences. 37: 843-55.

Prasanna, B.M. and Hoisington, D. (2003). Molecular breeding for maize improvement. An overview. Indian Journal of Biotechnology. 2: 85-98.

Pushpavalli, S.N.C.L., Sudan, C., Singh, N.N. and Prasanna, B.M. (2001). Differentiation of elite Indian maize hybrids using simple sequence repeat markers. Indian Journal of Genetics. 61: 304-308.

Revilla P., Soengas P., Malvar R.A., Cartea M.E. and Ordas A. (1998). Isozyme variation and historical relationships among the maize races of Spain. Maydica. 43:175-182.

Rohlf, F.J. (1989). In NTSYS-pc numerical taxonomy and multivariate analysis system. version 2.02, Exeter Publications, New York. USA.

Saghai-Maroof, M.A., Soliman, K.M., Jorgenson, R. and Allard, R.W. (1984). Ribosomal DNA spacer length polymorphism in barley. Mandelian inheritance, chromosomal location and population dynamics. Proceedings of the National Academy of Sciences of the United States of America. 81: 8014-8018.

Selvi, A., Nair, N.V., Noyer, J.L., Singh, N.K., Balasundarum, N., Bansal, K.C., Koundal, K.R. and Mohapatra, T. (2005). Genomic constitution and genetic relationship among the tropical and sub-tropical Indian sugarcane varieties revealed by AFLP. Crop Science. 45: 1750-1757.

Senior, M.L., Murphy, J.P., Goodman, M.M. and Stuber, C.W. (1998). Utility of SSRs for determining genetic similarities and relationships in maize using an agarose gel system. Crop Science. 38: 1088-1098.

Sharma, L., Prasanna, B.M. and Ramesh, B. (2010). Analysis of phenotypic and microsattelite-based diversity of maize landraces in India, especially from the North East Himalayan region. Genetica. 138: 619-631.

Smith J.S.C., Chin E.C.L., Shu H., Smith O.S., Wall S.J., Senior M.L., Mitchell S.E., Kresovich S. and Ziegle J. (1997). An evaluation of the utility of SSR loci as molecular markers in maize (Zea mays L.) comparisons with data from RFLPs and pedigree. Theoretical and Applied Genetics. 95:163-173.

Soleimani, V.D., Baum B.R. and Johnson, D.A. (2002). AFLP and pedigree-based genetic diversity estimates in modern cultivars of durum wheat [Triticum turgidum L. subsp. durum (Desf.) Husn.]. Theoretical and Applied Genetics. 104: 350-357.

Sun, G.L., William, M., Liu, J., Kasha, K.J. and Pauls, K.P. (2001). Microsatellite and RAPD polymorphisms in Ontario corn hybrids are related to the commercial sources and maturity ratings. Molecular Breeding, 7:13-24.

Tobias W., Eschholz Æ., Roland Peter Æ., Peter Stamp Æ., and Andreas H. (2008). Genetic diversity of Swiss maize (Zea mays L. ssp. mays) assessed with individuals and bulks on agarose gels. Genetic Resources and Crop Evolution. 55:971-983.

Vaz Patto, M.C., Satovic, Z., Pego, S. and Fevereiro, P. (2004). Assessing the genetic diversity of Portuguese maize germplasm using microsatellite markers. Euphytica. 137: 63-72.

Warburton, M.L., Xianchun, X., Crossa, J., Franco, J., Melchinger, A.E., Frisch, M., Bohn, M. and Hoisington, D. (2002). Genetic characterization of CIMMYT inbred maize lines and open pollinated populations using large scale fingerprinting methods. Crop Science. 42:18321840.

Yap, V.I. and Nelso, R.J. (1996). In WinBoot a programme for performing bootstrap analysis of binary data to determine the confidence limit of UPGMA-based dendogram, IRRI, Disc. Ser. No. 14. Int. Rice Rec. Inst., Manila, Philippines. 